\title{
Spontaneous Intracranial Hypotension: Case Series of Rare Clinical Presentations
}

\author{
N. Chaudhary, P. Cooper, S.P. Lownie, W. Ng, N. Duggal
}

\begin{abstract}
Background: Spontaneous intracranial hypotension (SIH) is an increasingly described entity, with over 70 cases reported in the literature. The classic triad includes orthostatic headache, diffuse pachymeningeal enhancement on magnetic resonance imaging (MRI) with gadolinium, and low cerebrospinal fluid pressure (CSF) in the lateral decubitus $\left(<60 \mathrm{~mm} \mathrm{H}_{2} \mathrm{O}\right)$ and sitting positions. Method: We present four rare clinical presentations of SIH, two of which have not been previously described in the literature, to the best of our knowledge. Results: Patient 1 presented with dyspnea, dysphagia, bilateral ptosis, diplopia and seizures. Patient 2 presented with a paradoxical positional pattern of orthostatic hypotension. In Patient 3, bilateral subdural hematomas (SDH) were encountered; while in Patient 4, a recurrent unilateral SDH requiring multiple surgical interventions was demonstrated. Conclusion: Although uncommon clinical presentations, all four cases of intracranial hypotension were spontaneous, demonstrated diagnostic MRI findings, and responded favorably to blood patches or saline injections.
\end{abstract}

RÉSUMÉ: Hypotension intracrânienne spontanée : présentations cliniques rares. Contexte : L'hypotension intracrânienne spontanée (HIS) est une entité décrite de plus en plus fréquemment dont il existe plus de 70 cas dans la littérature. La triade classique comprend la céphalée orthostatique, un rehaussement pachyméningé à l'imagerie par résonance magnétique (IRM) avec gadolinium et une pression du liquide céphalorachidien basse en décubitus latéral ( $<60 \mathrm{~mm} \mathrm{H2O}$ ) et en position assise. Méthode : Nous présentons les observations de quatre patients atteints de HIS dont le mode de présentation est rare. À notre connaissance, deux de ces modes de présentation n'ont jamais été décrits dans la littérature. Résultats : Le premier patient a consulté pour dyspnée, dysphagie, ptose bilatérale, diplopie et convulsions. Le deuxième patient a consulté pour une hypotension orthostatique dont la modalité positionnelle était paradoxale. Le troisième patient était porteur d'hématomes sous-duraux (HSD) bilatéraux et le quatrième patient présentait un HSD unilatéral récurrent nécessitant plusieurs chirurgies. Conclusion : Bien que ces tableaux cliniques soient peu fréquents, ces quatre cas d'hypotension intracrânienne étaient spontanés, avaient des observations à l'IRM qui étaient diagnostiques et ont répondu favorablement à des "blood patches" ou à des injections de solution physiologique.

Can. J. Neurol. Sci. 2011; 38: 54-58

Spontaneous intracranial hypotension $(\mathrm{SIH})$ is an increasingly described entity, with over 70 cases reported in the literature $^{1-22}$. Spontaneous intracranial hypotension was initially described by Schaltenbrand in 1938, as a syndrome characterized by orthostatic headache ${ }^{23}$. According to the International Headache Society Classification, the headache worsens within 15 minutes of assuming the upright position, and dissipates within 30 minutes of resuming the recumbent position $^{24}$. Associated symptoms may include nausea and vomiting, blurred vision, bitemporal hemianopsia, diplopia, facial numbness or weakness, tinnitus, hearing loss, vertigo, galactorrhea, neck pain, back pain and radicular symptoms ${ }^{25}$. Since its initial description, SIH has been recognized as a triad of orthostatic headache, diffuse pachymeningeal enhancement on magnetic resonance imaging (MRI) with gadolinium, and low cerebrospinal fluid (CSF) pressure in the lateral decubitus $(<60$ $\mathrm{mm} \mathrm{H}_{2} \mathrm{O}$ ) and sitting positions ${ }^{1}$.

We present four rare clinical presentations of SIH, two of which have not been previously described in the literature, to the best of our knowledge. Patient 1 presented with ptosis, diplopia, dyspnea, dysphagia, and complex partial seizures. Patient 2

\footnotetext{
From the Division of Neurosurgery (NC, PC, SPL, WN, ND), Clinical Neurological Sciences (NC, SPL, WN, ND), Division of Neurology (PC), London Health Sciences Center, London, Ontario, Canada.

Received March 10, 2010. Final Revisions Submitted July 26, 2010. Correspondence to: Neil Duggal, Division of Neurosurgery, University Hospital, London Health Sciences Center, 339 Windermere Rd, London, Ontario, N6A 5A5, Canada.
} 
presented with a paradoxical positional pattern of orthostatic hypotension. In Patient 3, bilateral subdural hematomas (SDH) were encountered; while in Patient 4, a recurrent unilateral SDH was demonstrated.

\section{Case Presentations}

\section{Patient 1}

Patient 1 is a 60 year-old man who presented with a decreased level of consciousness. This was preceded by a one month history of intermittent ptosis, diplopia, dyspnea, and dysphagia. On examination, he was difficult to arouse, had bilateral ptosis, and was profoundly dyspneic. Shortly after presentation, he had a complex partial seizure involving left sided facial twitching. A lumbar puncture revealed an opening pressure of $40 \mathrm{mmHg}$, and MRI with gadolinium demonstrated small bilateral subdural hygromas, with dural enhancement (Figure 1). Computed tomogram (CT) myelogram revealed foci of contrast extending from the dural tube into the foramina of T6/7, T7/8, T11/12, and L5/S1. A differential diagnosis for these foci included asymmetric nerve root sleeves or small perineural cysts giving rise to potential dural tears. Treatment with a $20 \mathrm{cc}$ blood patch in the lumbar spine led to complete resolution of symptoms within one hour of administration. This patient remained symptom-free at one year follow-up.

\section{Patient 2}

Patient 2 is a 42-year-old man who presented with a unilateral throbbing headache, which was exacerbated with the Valsalva maneuver and in the supine position. It was accompanied by nausea and tinnitus. The onset of headache coincided with a chiropractic manipulation. Neurological examination was unremarkable. Magnetic resonance imaging with gadolinium demonstrated dural thickening and enhancement, with drooping of the diencephalon (Figure 2). An initial $17 \mathrm{~mL}$ autologous blood patch led to transient headache resolution, and a second blood patch was performed one month later. This patient will be followed for any further recurrence.

\section{Patient 3}

Patient 3 is a 54 year-old man who presented with a progressive headache that was exacerbated in the upright position, and associated with vomiting and confusion. These symptoms occurred three weeks following a presumed sinus infection during which, he had an episode of violent sneezing leading to purulent nasal discharge. Physical examination did not demonstrate any evidence of CSF leak. Magnetic resonance imaging with gadolinium demonstrated a bilateral SDH, as well as, diencephalon drooping and brainstem elongation (Figure 3). Intervention included two lumbar saline infusions of $40 \mathrm{cc}$ each at Day 1 and Day 4, resulting in complete resolution of his symptoms. This patient remains symptom-free at a two month follow-up clinic.

\section{Patient 4}

Patient 4 is 37-year-old man who presented with a right sided acute on chronic SDH. On the day of admission, he was found unconscious. On arrival to hospital, his clinical status improved and he was awake and alert. He was admitted for observation, and on the sixth day of admission, he became drowsy, and required burr hole drainage. The only antecedent event included

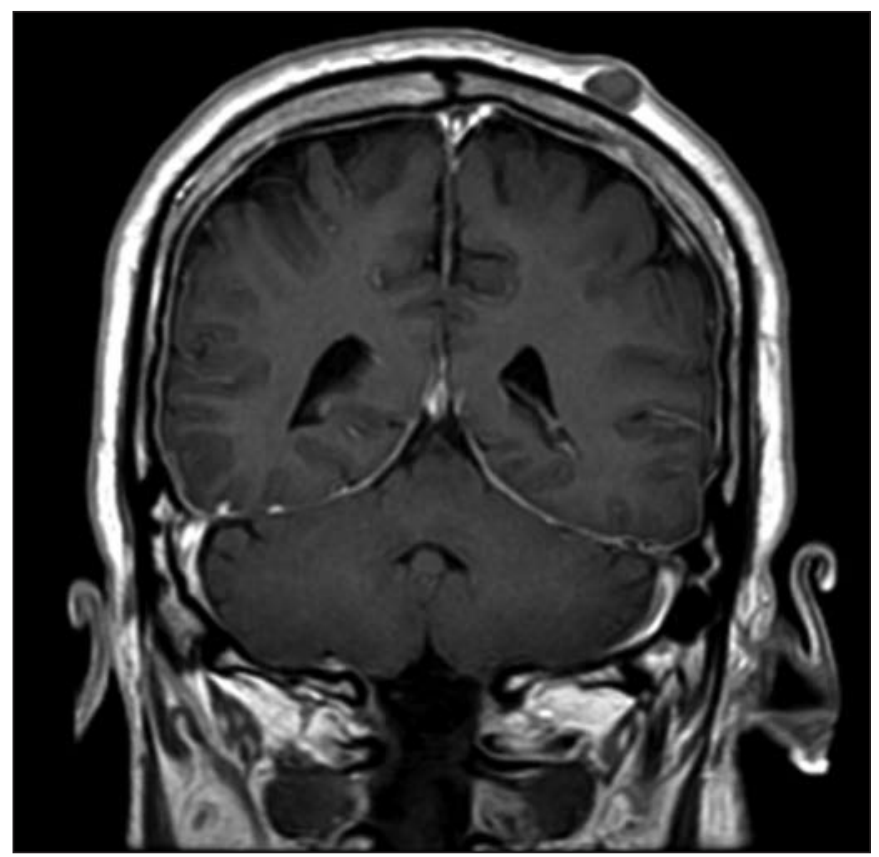

Figure 1: MRI T1 weighted coronal image demonstrating dural enhancement with bilateral subdural hygromas.

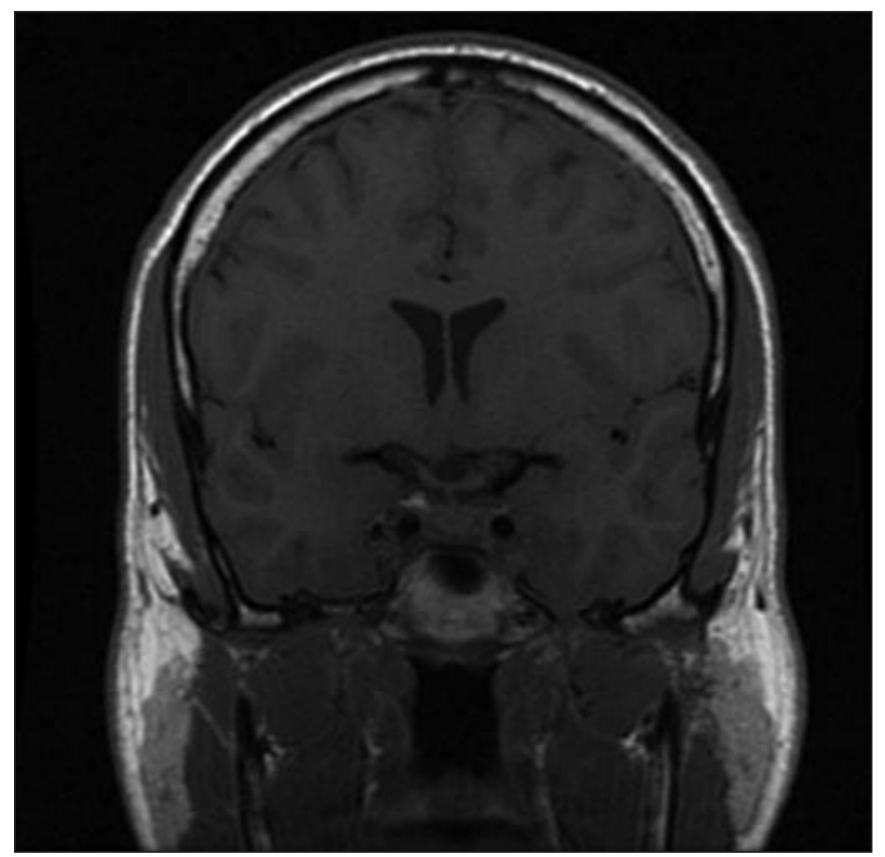

Figure 2: MRI TI weighted coronal image demonstrating dural thickening and enhancement, with drooping of the diencephalon. 

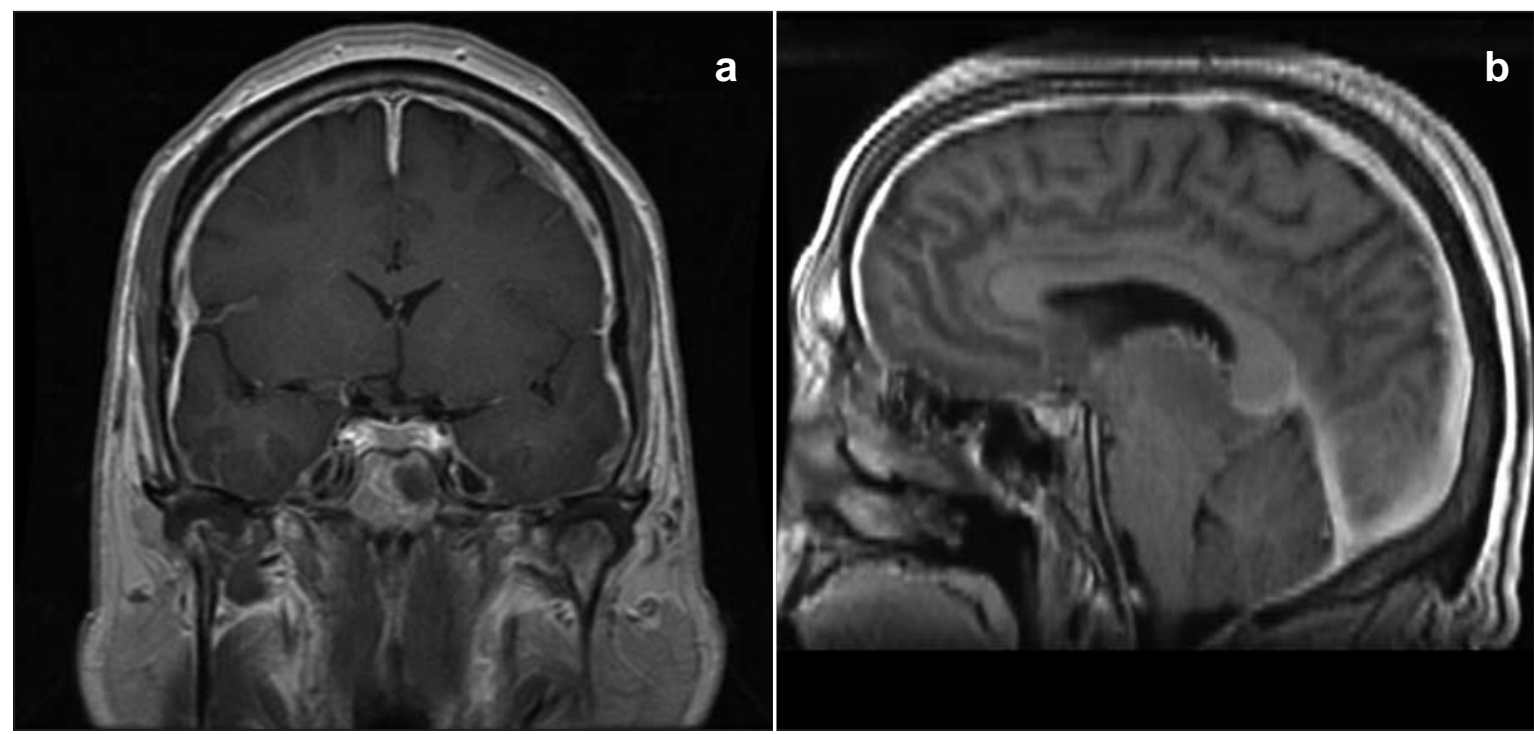

Figure 3: MRI T1 weighted image demonstrating dural thickening with bilateral SDH; and downward descent of the brain with diencephalon drooping and brainstem elongtation. a) coronal image, b) sagittal image.

a chiropractic neck manipulation 2 weeks prior to presentation, as well as trivial trauma to the head while playing soccer, on the day prior to admission. Approximately one week following his burr hole evacuation, he had progressive drowsiness, and required intubation. A CT demonstrated reaccumulation of the $\mathrm{SDH}$, and the patient was taken to the operating room for a craniotomy. Postoperatively, he was opening his eyes only momentarily, had no verbal output, but was obeying commands with all four extremities. In addition, he developed complex partial seizures. Failing to improve, an MRI was performed and raised the possibility of intracranial hypotension (Figure 4). He returned to the operating for a second craniotomy at this time. On postoperative day one, the patient stopped localizing on motor exam, and responded favorably to being put in the Trendelenburg position, improving to become alert and oriented within 24 hours. When the head of the bed was elevated to 0 degrees, the patient developed a mild left pronator drift. The CT myelography suggested a potential leak in the thoracic spine, and a $20 \mathrm{cc}$ autologous epidural blood patch was placed at the T12L1 level. The head of the bed was gradually raised and the
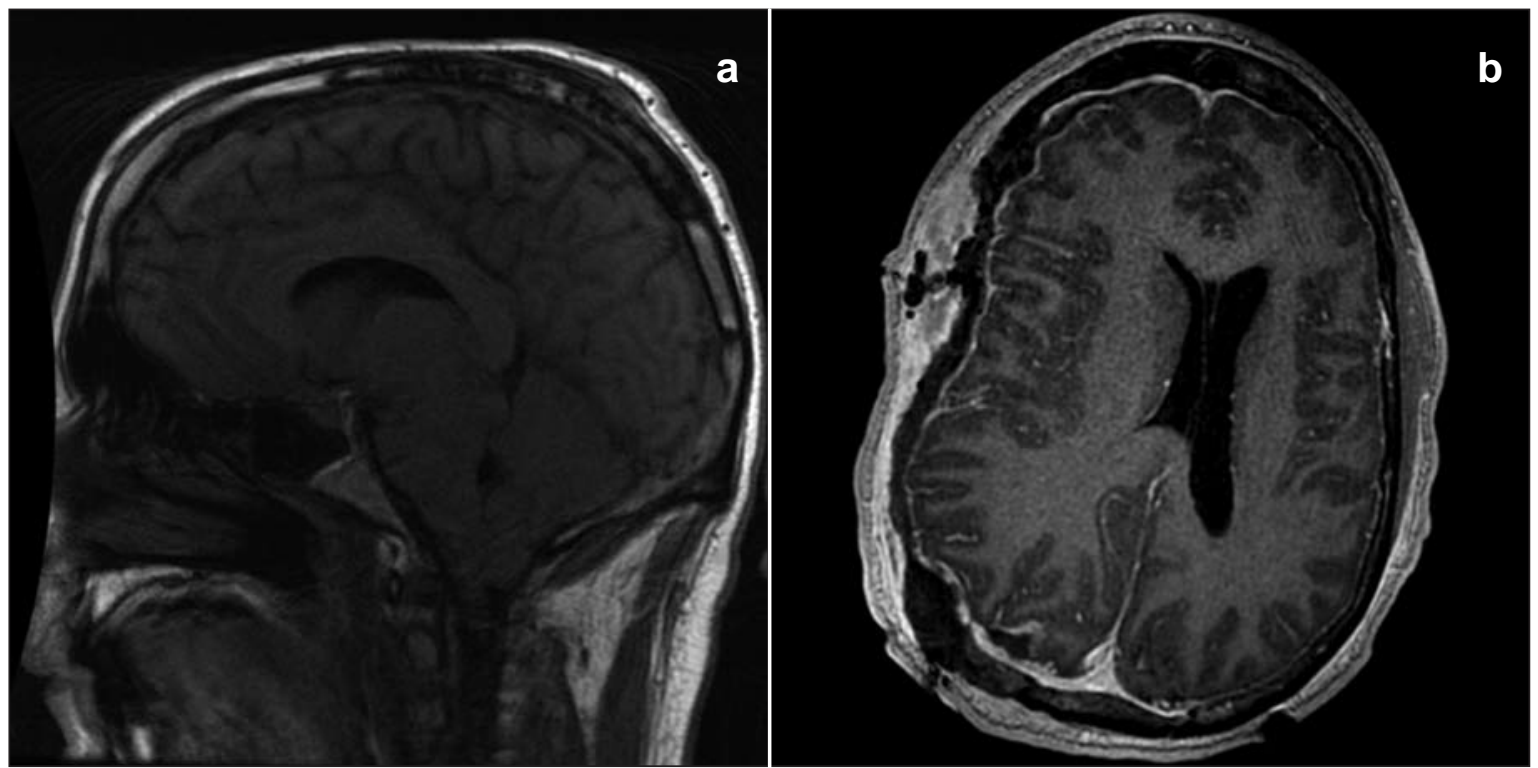

Figure 4: MRI T1 weighted images demonstrating low lying cerebellar tonsils and midbrain distortion, as well as, a right sided subdural fluid collection. a) sagittal image, b) axial image. 
patient was mobilized. Subsequent MRI demonstrated resolution of SIH and no recurrent SDH. This patient remained symptomfree at a six month follow-up.

\section{Discussion}

Intracranial hypotension is most often iatrogenic following a procedures including lumbar puncture, spinal anesthesia, or cranial/spinal surgery ${ }^{1,26}$. In contrast, most cases of SIH occur following a spontaneous CSF leak from a meningeal or arachnoid diverticulum, or perineural $\operatorname{cyst}^{1,6,27,28}$. Other precipitants include vigorous exercise or violent coughing ${ }^{1,6,29-33}$. No iatrogenic cause was identified in any our cases. Patient 1 was demonstrated to have potential dural tears secondary to perineural cysts, while Patients 2, 3 and 4 presumably had traumatic etiologies including, respectively, a chiropractic manipulation, an episode of violent sneezing, and a trivial injury during a game of soccer, in the context of previous chiropractic neck manipulation.

The Munro-Kellie hypothesis has been proposed to explain the mechanism underlying the development of SIH. In SIH, vascular dilation is thought to compensate for reduced CSF volume, with the predominance of vasodilation occurring in the venous system ${ }^{34,35}$. As a result, MRI findings include venous engorgement, subdural hematoma or hygroma, enlargement of the pituitary gland and downward displacement of the brainstem. As seen in Patients 3 and 4, the number of bilateral or unilateral SDHs in the literature remains small. Additional MRI findings include pachymeningeal enhancement, while the leptomeninges are unaffected. A proposed explanation is that the dura lacks tight junctions and does not contribute to the blood-brain barrier. This is in contrast to the tight junctions in the arachnoid and pia mater. Consequently, extravasation of fluid occurs into the subdural space $^{36}$. Resultant MRI findings in SIH include gadolinium enhancement and thickening of the pachymeninges without involvement of the lepto-meninges, as was seen in all four of our patients. Further, MRI may demonstrate a decrease in the size of the basal cisterns and ventricles, flattening of the optic chiasm and pons, and herniation of the cerebellar tonsils ${ }^{1}$. Most recently, a pathophysiologic theory based on the spinal venous drainage system anatomy has been proposed. These authors propose that CSF leaks result from epidural hypotension maintained by inferior vena cava outflow to the heart, and that blood patches reverse the CSF-blood gradient within the epidural space along the spinal $\operatorname{cord}^{37}$.

Theories to explain the clinical manifestations of SIH include caudal descent of the brain, as the buoyancy of the brain decreases with a smaller volume of CSF, as well as, by venous dilation of pain-sensitive structures. As the buoyant force decreases, bridging veins may rupture as the brain is pulled from the dura, resulting in subdural collections as seen in Patients 1, 3 and $4^{38}$. As the brain descends, traction occurs on pain-sensitive structures including the meninges, veins, cranial nerves and the superior three cervical nerves. This theory accounts for clinical manifestations of SIH including bilateral ptosis, diplopia, facial numbness or tingling, facial weakness; hearing loss, vertigo and tinnitus; and neck pain and radiculopathy. This explanation accounts for the cranial nerve findings in Patient 1.

When conservative measures including bed rest, analgesia and fluid resuscitation fail to reverse symptoms, more invasive intervention options include blood patches, saline infusions, percutaneous fibrin glue and operative interventions ${ }^{20,33}$. In cases of an intractable headache, a large-volume blood patch (>20 mL) is preferred ${ }^{9,29}$. Anecdotal evidence for blood patches are based on the observation of fewer CSF leaks in cases of traumatic or bloody lumbar punctures. An initial blood patch is associated with the resolution of symptoms in $85-90 \%$ of cases, and as high as $98 \%$ with a repeat patch ${ }^{28,36}$. The blood patch is thought to provide a transient increase in CSF volume and a tamponade effect, while promoting the development of scar tissue. Alternatively, saline infusions over a period of a several days may increase CSF volume, while the natural healing process occurs $^{38}$. Definitive treatment includes surgical correction of a dural tear or meningeal diverticula, or packing of the epidural space with Gelfoam or fibrin glue. Finally, bilateral burr holes or a craniectomy are reserved for extreme cases of SDH or hygromas $^{38}$. In our case series, symptoms were successfully reversed with blood patches in Patients 1,2, and 4; and with saline injections in Patient 3. Individual physician preference determined whether a blood patch or saline infusion was selected for management in our case series. Patient 3's bilateral SDH was managed conservatively, while Patient 4 required multiple surgical evacuations of his SDH.

\section{CONCLUSION}

To date, over 70 cases of SIH have been reported in the literature $^{1-22}$. To the best of our knowledge, no previous reports in the literature have described SIH presenting with seizure accompanied by ptosis, diplopia, dyspnea, and dysphagia. Consistent with $\mathrm{SIH}$, these symptoms were exacerbated with postural change, met the diagnostic imaging criteria of SIH and resolved with a blood patch. With respect to the witnessed seizure, this may have been related to traction on the structures of the brain secondary to low intracranial pressure. In Patient 2, chiropractic manipulation may have precipitated the CSF leak. Although this paradoxical headache pattern has not previously been described in the literature, the MRI is consistent with SIH and there was a favorable response to the blood patch. In Patient 3 , an episode of violent sneezing may have precipitated an occult CSF leak. In Patient 4, neck manipulation may have precipitated a CSF leak, while the soccer injury may have contributed to the acute on chronic SDH. Although SDH is a feature commonly seen in SIH, bilateral SDHs and a recurrent unilateral SDH requiring multiple surgical interventions are much less common. Our case series highlights the variability of SIH clinical presentations. All four cases, however, were spontaneous, demonstrated MRI findings consistent with hypotension, and responded favorably to blood patches or saline injections.

\section{REFERENCES}

1. Ferrante E, Savino A, Sances F, et al. Spontaneous intracranial hypotension syndrome: report of twelve cases. Headache. 2004; 44:615-22.

2. Binder DK, Dillon WP, Fishman R, et al. Intrathecal saline infusion in the treatment of obtundation associated with spontaneous intracranial hypotension: technical case report. Neurosurgery. 2002;51:830-7.

3. Haritanti A, Karacostas D, Drevelengas A, et al. Spontaneous intracranial hypotension: clinical and neuroimaging findings in six cases with literature review. Eur J Radiol. 2009;69(2):253-9. 
4. Moayeri NN, Henson JW, Schaeffer PW, et al. Spinal dural enhancement on magnetic resonance imaging associated with spontaneous intracranial hypotension. J Neurosurg. 1998;88: 912-8.

5. Nakajima H, Sakai T, Aoki N, et al. Bilateral chronic subdural hematomas associated with intracranial hypotension: case report. Neurol Med Chir (Tokyo). 1996;36:647-9.

6. Rando TA, Fishman RA. Spontaneous intracranial hypotension: report of two cases and review of the literature. Neurology. 1992;42:481-7.

7. Renowden SA, Gregory R, Hyman N, et al. Spontaneous intracranial hypotension. J Neurol Neurosurg Psychiatry. 1995; 59:511-5.

8. Sayer FT, Bodelsson M, Larsson E, et al. Spontaneous intracranial hypotension resulting in coma: case report. Neurosurgery. 2006; 58:E204-5.

9. Schievink WI, Meyer FB, Atkinson JLD, et al. Spontaneous spinal cerebrovascular fluid leaks and intracranial hypotension. J Neurosurg. 1996;84:598-605

10. Schoffer KL, Benstead TJ, Grant I. Spontaneous intracranial hypotension in the absence of magnetic resonance imaging abnormalities. Can J Neurol Sci. 2002;29:253-7.

11. Vaidhyanath R, Kenningham R, Khan A, et al. Spontaneous intracranial hypotension: a cause of severe acute headache. Emerg Med. 2007;J24:739-41.

12. Weber WEJ, Heidandal GAK, de Krom M. Primary intracranial hypotension and abnormal radionuclide cisternography. Clin Neurol Neurosurg. 1991;93(1):55-60.

13. Zada G, Pezeshkian P, Giannotta S. Spontaneous intracranial hypotension and immediate improvement following epidural blood patch placement demonstrated by intracranial pressure monitoring. J Neurosurg. 2007;106:1089-90.

14. Arai M, Takada T. A case of spontaneous intracranial hypotension with multiple CSF leaks in the thoracic region. Rinsho Shinkeigaku [article in Japanese]. 2005;45(9):679-81.

15. Asano N, Taki K, Kondo T, et al. A case of spontaneous intracranial hypotension effectively treated with cervical epidural blood patch. Masui [article in Japanese]. 2004;53(10):1185-8.

16. Nakajima M, Hirano T, Sasamoto N, et al. A case of spontaneous intracranial hypotension without any history of positional headaches. No To Shinkei [article in Japanese]. 2002;54(11): 991-5.

17. Rojas JI, Romano M, Patrucco L, et al. Spontaneous intracranial hypotension. Medicinia [article in Spanish]. 2006;66(5):447-9.

18. Tijssen CC, van Gulik S, Sluzewski M, et al. Ned Tijdschr Geneeskd [article in Dutch]. 2005;149(18):996-1000.

19. Atkinson JLD, Weinshenker BG, Miller GM, et al. Acquired chiari I malformation secondary to spontaneous spinal cerebrospinal fluid leakage and chronic intracranial hypotension syndrome in seven cases. J Neurosurg. 1998;88:237-42.

20. Tsui EYK, Ng SH, Cheung YK, et al. Spontaneous intracranial hypotension with diffuse dural enhancement of the spinal canal and transient enlargement of the pituitary gland. Eur J Radiol. 2001;38:59-63.
21. Ferrante E, Savino A, Bioschi A, et al. Transient oculomotor cranial palsy in spontaneous intracranial hypotension. J Neurol Sci. 1998;42(3): 177-80.

22. Shievink WI, Reimer R, Folger WN. Surgical treatment of spontaneous intracranial hypotension associated with a spinal arachnoid diverticulum. J Neurosurg. 1994;80:736-9.

23. Schaltenbrand G. Neuere anschauugen zur pathophysiologie der liquorzirkulation. Zentralbl Neurochir. 1938;3:290-300.

24. The International Classification of Headache Disorders, 2nd ed. International Headache Society in. Cephalalgia. 2004;24 Suppl 1):16-7.

25. Capobianco DJ, Kuczler FJ. Case report: primary intracranial hypotension. Mil Med. 1990;155:64-6.

26. Raskin NH. Lumbar puncture headache: a review. Headache. 1990; 30:197-200

27. Chung SJ, Kim JS, Lee MC. Syndrome of cerebral spinal fluid hypovolemia: clinical and imaging features and outcomes. Neurology. 2000;55:1321-7.

28. Leibold RA, Yealy DM, Coppolla M, et al. Post-dural-puncture headhache: characteristics, management and prevention. Ann Emerg Med. 1993;22:1863-70.

29. Mokri B, Maher CO, Sencakova D. Spontaneous CSF leaks: underlying disorder of connective tissue. Neurology. 2002;58: 814-6.

30. Schrjver I, Schievink WI, Godfrey M, et al. Spontaneous spinal cerebrospinal fluid leaks and minor skeletal features of Marfan's syndrome: a microfibrillopathy. J Neurosurg. 2002;96:483-9.

31. Schoffer KL, Benstead TJ, Grant I. Spontaneous intracranial hypotension in the absence of magnetic resonance imaging abnormalities. Can J Neurol Sci. 2002;29:253-7.

32. Garcia-Albea E, Cabrera F, Tejeiro J, et al. Delayed post-exertional headache, intracranial hypotension, and racket sports. J Neurol Neurosurg Psychiatry. 1992;55:975.

33. Schievink WI, Morreale VM, Atkinson JLD, et al. Surgical treatment of spontaneous spinal cerebrospinal fluid leaks. J Neurosurg. 1998;88:243-6.

34. Fishman RA, Dillon WP. Dural enhancement and cerebral displacement secondary to intracranial hypotension. Neurology. 1993:43:609-11.

35. Paldino M, Mogilner AY, Tenner MS. Intracranial hypotension syndrome: a comprehensive review. Neurosurg Focus. 2003;12 (6):ECP2

36. Brightbill TC, Goodwin RS, Ford RF. Magnetic resonance imaging of the intracranial hypotension syndrome with pathophsyiologic correlation. Headache. 2000;40:292-9.

37. Franzini A, Messina G, Nazzi V, et al. Spontaneous intracranial hypotension syndrome: a novel speculative hypophysiologic hypothesis and a novel patch method in a series of 28 consecutive patients. J Neurosurg. 2010;112:300-6.

38. Lay C, Campbell K, Mokri B. Low cerebrospinal fluid headache, in Goadsby PJ, Silberstein SD, editors. Headache. Boston: Butterworth-Heinemann; 1997. p. 355-67. 